\title{
CORPO EM NIETZSCHE: UMA LEITURA DA II DISSERTAÇÃO DA GENEALOGIA DA MORAL
}

\author{
Julie Christie Damasceno Leal ${ }^{1}$ \\ Universidade Federal do Pará (UFPA)
}

\begin{abstract}
RESUMO:
O presente artigo tem por objetivo investigar a noção de corpo no pensamento do filósofo alemão Friedrich Nietzsche, mais especificamente a partir de uma leitura de alguns temas presentes na II Dissertação da Genealogia da Moral, basilares para se mobilizar tal noção. Dentre as questões elencadas encontram-se o papel da consciência, a memória, o esquecimento, o sentimento de culpa e a figura do criminoso que, partindose da leitura a que nos propomos, podem ser de fundamental importância para se pensar o corpo em Nietzsche.
\end{abstract}

PALAVRAS-CHAVE: Corpo; Nietzsche; Genealogia da Moral.

\section{BODY IN NIETZSCHE: A READING OF THE SECOND DISSERTATION OF THE GENEALOGY OF MORALS}

\begin{abstract}
:
This paper aims to investigate the notion of body at the thought of German philosopher Friedrich Nietzsche, specifically from a reading of some themes in the second Dissertation of Genealogy of Morals, basic to mobilize such a notion. Among the listed issues are the role of consciousness, memory, forgetfulness, guilt and the criminal figure, starting from the reading that we propose, can be extremely important to think about the body Nietzsche.
\end{abstract}

KEYWORDS: Body; Nietzsche; Genealogy of Morals.

O corpo é objeto dos mais variados estudos na contemporaneidade. Desde abordagens literárias e sociolinguísticas até tessituras científicas e

\footnotetext{
${ }^{1}$ Mestranda em Filosofia pelo Programa de Pós-Graduação em Filosofia da Universidade Federal do Pará (UFPA), Pará - Brasil. E-mail: julychris2012@gmail.com
} 
filosóficas, todas as áreas de conhecimento vem trazendo contribuições bastante significativas no que se refere à noção de corpo. Mas apesar do interesse crescente por tal temática ser algo realmente notório, Courtine (2013) afirmará que tamanha veemência ao corpo é um fenômeno recente: "O corpo, de fato, é uma invenção teórica recente: antes da virada do século $\mathrm{XX}$, ele não exercia senão um papel secundário na cena do teatro filosófico onde, desde Descartes, a alma parecia exercer o papel principal" (COURTINE, 2013, p. 12).

Partindo da afirmação de Courtine apresentada acima, nos propomos refletir sobre o corpo na história do pensamento recente, mais especificamente a partir da perspectiva de Friedrich Nietzsche. É válido frisar que na contemporaneidade, o corpo passou de um personagem secundário na história da humanidade, subjugado, no seio da filosofia, pela soberania da alma, para um personagem central nos debates filosóficos e sociológicos mais acalorados.

$\mathrm{Na}$ atualidade, o corpo pode ser pensado pelos mais variados vieses, uma vez que ele está em constante destaque, seja pelos holofotes e câmeras de televisão e cinema que põem em evidência os corpos dos artistas, modelos e celebridades (re)criando padrões de beleza física que são comercializados para a massa; seja pelo papel estratégico desempenhado pelo corpo nas novas campanhas estatais de valorização da saúde, com estímulo à prática de exercícios físicos periódicos e estilo de vida saudáveis, seja também no que tange ao corpo do prisioneiro e mesmo do condenado à morte, corpo esse desprovido de liberdade, que se por um lado, passa a ser assistido pelas políticas de direitos humanos internacionais que proíbem o desrespeito à integridade física, psíquica e moral, por outro,tem um aumento de vigilância sobre o seu corpo, justamente para que não cometa suicídio, pois a pena precisa ser aplicada. Em todas as situações descritas, o corpo assume lugar central.

Contudo, diante de um amplo domínio de possibilidades de se pensar o corpo, conforme vimos, decidiu-se pensá-lo com Nietzsche, para quem toda a história da filosofia não passa de uma má compreensão sobre o corpo, uma vez que, colocando-se de lado todos os mecanismos reguladores e modificadores do corpo, desde leis, instituições sociais (como a Igreja) até procedimentos cirúrgicos, produtos, técnicas para uma reestruturação física do homem, acima disso tudo está o fato, basilar, de que o homem é apenas mais um animal entre tantos que vagam pelo mundo, com a diferença de que é o único a teorizar sobre sua vida e sua morte, capaz de estabelecer teorias, criar teses, mentir, prometer.

$\mathrm{O}$ ato de prometer, em um primeiro momento, apresenta-se como um procedimento simples, efetuado no dia a dia, nos diálogos mais corriqueiros, nas situações mais banais. Mas a promessa encerra em si diretrizes que norteiam o posicionamento do homem e sua visão no e sobre o mundo e si mesmo. Prometer é tentar, sob circunstâncias, pouco concretas, efetuar uma 
projeção futura, tentando abarcar possibilidades plausíveis de concretização de algo que foi estabelecido, mas que não possui qualquer probabilidade concreta de ocorrer efetivamente em um tempo posterior. Tentar dar contar do que há por vir, estabelecendo parâmetros para tal acontecimento, é algo que o homem projeta sem se dar conta muitas vezes de que uma simples promessa está, para além do seu controle e vontade.

Mas na promessa também é possível conceber outras perspectivas, partindo-se do pensamento do filósofo germânico Nietzsche: seria o ato de prometer uma forma de disciplinar o homem, ou melhor, disciplinar o animal homem? A promessa, o comprometer-se, gera no homem a necessidade da lembrança. Esse exercício, por assim dizer, de reforço da lembrança gera efeitos colaterais no homem que, conscientemente ou não, resultam em consequências que vão para além da lembrança ou esquecimento de um compromisso: podem também, hiperatrofiadas, gerar problemas no campo psíquico, como também físico.

Para melhor visualização do que se está abordando, cria-se a imagem do homem que, diante de uma ofensa, não consegue superá-la, ou esquecer a injúria sofrida. Tal homem, preso à lembrança constante, tende a se inserir em um plano no qual se torna, por assim dizer, escravo de tal lembrança, o que resultará em consequências, nem sempre simplórias, ao seu psíquico, que, em muitos casos, repassa ao corpo as aflições psicológicas. Temos, desse modo, através da memória, um homem enfermo.

No âmbito do cultural, mais precisamente do religioso, tal mecanismo de adoecimento do homem se mostra muito mais eficaz e eficiente. Há muito, determinadas religiões abandonaram a busca pelo sagrado e o sentimento catártico que marcavam as celebrações de cunho místico nos primórdios da civilização humana, dando lugar ao jogo de poder, através da força e da ideologia, na busca pelo nivelamento do homem e seu posterior arrebanhamento. Nietzsche explicou com profundidade as relações que marcaram os senhores e os escravos e a inversão de valores que resultou através da figura, principalmente, do sacerdote, que tornou aquilo que era forte e saudável em errôneo e pecaminoso; ao passo que a fraqueza e a perda da autonomia se converteram no ideal a ser postulado como o desejável.

Com tal inversão, fez-se necessário criar mecanismos que sustentassem ideologicamente a postura do homem fraco como o aceitável. Inventou-se, dessa forma, o perdão, bem como o paraíso, inferno, alma, diabo, livre-arbítrio, dentre outros, com o intuito único de por o homem em um estado de constante vigília contra aquilo que a Igreja postulou como pecado.

Desde o seu nascimento, o homem é marcado pelo estigma do chamado pecado original, conforme a ideologia cristã. Impõe-se, dessa forma, e já nos primórdios da vida do indivíduo, um sentimento de culpa, criado para que se sinta culpado, para que comece a desconfiar ou recear 
pela sua própria conduta e pensamento. O sentimento de culpa, no decorrer da vida, deve não apenas ser mantido, como também acentuado: preguiça, glutonice, raiva, homossexualismo, desejos carnais, luxúria etc., são agora desejos que precisam ser reprimidos em nome de uma vida ascética. A lembrança atua no sentido de que o homem não pode esquecer aquilo que é considerado pecado, para não praticar, ou se o fez, não esquecer. A figura do sacerdote atua no sentido de ampliar, sempre que possível, tal sentimento de culpa, muitas vezes por coisas que o indivíduo nem concretizou, mas somente pensou.

Dessa forma, o não esquecimento se torna um mecanismo de controle e adoecimento do homem, que internaliza determinadas ideologias que regulam sua forma de agir e, muitas vezes, de pensar. O livre-arbítrio é a armadilha criada para que o homem se creia livre, que o leva a acreditar pode agir conforme a sua consciência. Mas tal liberdade é condicionada, pois o homem atua delimitado por um campo de ação previamente demarcado pelas religiões. O "não mentirás", assim posto, torna-se um mandamento, por exemplo, no qual está explícito a não liberdade do homem.

Ao viver sob estigmas, tais como pecado, culpa e má consciência, o homem reprimiu-se e internalizou sentimentos que o tornaram submisso e controlável, dócil para a sua inserção no rebanho. Não é sem razão que Nietzsche aponta para o esquecimento como uma forma de romper com tal sistema de doutrinamento e nivelamento do homem:

\footnotetext{
Esquecer não é uma simples vis inertiae [força inercial], como creem os superficiais, mas uma força inibidora ativa, positiva no mais rigoroso sentido, graças à qual o que é por nós experimentado, vivenciado, em nós acolhido, não penetra mais em nossa consciência, no estado de digestão (ao qual poderíamos chamar "assimilação psíquica"), do que todo o multiforme processo da nossa nutrição corporal ou "assimilação física" (NIETZSCHE, 1998, §1, p.47).
}

$\mathrm{O}$ esquecimento, assim posto, funciona como um mecanismo que possibilita o escoamento, por assim dizer, de lembranças que atuam de modo negativo sobre o psique do homem, permitindo, em consequência, a entrada do novo, do inédito, em uma troca contínua para que a consciência não se fixe em vivências ou experiências traumáticas, potencialmente enfermiças, que, como já foi dito, também atuam sobre o corpo, debilitandoo, uma vez que mente e corpo se coadunam, complementando-se para a constituição integral do sujeito, entendendo-se mente como espírito, ou alma, em algumas vertentes filosóficas.

Reafirma-se, portanto, a função positiva e ativa do esquecimento na vida dos indivíduos, pois este se configura como uma espécie de zelador da ordem psíquica. O homem incapaz de esquecer, o animal que promete, 
acredita na factibilidade do porvir, no vir a ser, o que se mostra errôneo, pois prometer é contrair dívida.

Tal faculdade, a de prometer, mostra-se como uma atividade reativa ao homem, pois, neste, a sua força vital, direcionada ao que era instintivo, agora, com a promessa, é desviada, é repartida, fragmentada, desconfigurando um sistema orgânico que antes operava adequadamente:

Como foi possível que no reino animal, em que os instintos operavam organicamente, espontaneamente, sem deliberação, mas de forma perfeita, certeira, surgisse a consciência, aparecesse a memória? Cada impulso, cada força impele a agir: o animal come, bebe, anda, tudo nele faz parte de um circuito orgânico em que as energias são certeiramente canalizadas. Nietzsche destaca a perfeição dos processos instintivos, o devir harmonioso dos corpos (BARRENECHEA, 2006, p. 31).

Dívida também pode ser vista, sob certo aspecto, como culpa, uma vez que efetuada a promessa e a mesma não se realizando, o homem é tomado por um sentimento de culpa, de pesar, pois a sua prévia crença de controle temporal, não se efetivou. Aquele que promete e não consegue cumprir, está inserido em dois planos adversos aos quais acaba por se prender: ao realizar a promessa propriamente dita, inserindo-a forçosamente em um contexto temporal, perdendo-se, assim, no empreendimento da promessa, o que lhe custa esforço e tempo; a da frustração mediante a não realização da promessa, que o situa em um âmbito que pode ser qualificado como mais angustiante do que o primeiro, pois se na primeira, ou seja, no ato da promessa o sujeito comprometia-se em um particular espaço de tempo, na desilusão da não realização da promessa tais sentimentos de incapacidade, de decepção, podem acompanhá-lo durante toda a sua existência. Pode-se afirmar, portanto, que o homem é um animal doente, posto ser o único capaz de prometer, de se mostrar flexível, volúvel diante das circunstâncias fato que deseja, a todo momento, controlar, dominar, como o faz, ou tenta fazê-lo, com a natureza, com a sua vida e o seu destino. Diante do insucesso e da instabilidade, sofre e angustia-se:

O homem é o animal doente, o mais e prolongadamente doente entre todos os animais porque é também o animal não fixado, sendo assim o grande experimentador consigo mesmo. Essa autoexperimentação - que acarreta a instabilidade, a mutabilidade e insegurança - pressupõe mal-estar, sofrimento, insatisfação, ânsia, insaciedade, permanente, mas também desafio e combate, repto lançado ao destino, disputa por domínio sobre animais, natureza e deuses (também e sobretudo sobre si mesmo) (GIACÓIA JUNIOR, 2013, p.24).

A força do esquecimento reside na sua capacidade de introduzir a dissipação na memória, do esfacelamento dos resíduos memoriais que atuavam sobre o indivíduo de forma contraproducente. O fisiológico está 
representado na questão abordada através do processo digestivo, uma vez que o corpo está intrinsecamente ligado ao ato de nutrição, que consiste na assimilação daquilo que é benéfico ao corpo e expurgo do excesso ou prejudicial. Esse sistema pode ser claramente associado ao procedimento de memorização e esquecimento: aquilo que se configura saudável deve ser retido na memória, em contrapartida, os resíduos negativos devem ser expelidos, pois se caracterizam como formas debilitantes das forças constituintes da psique humana.

O homem, como um todo saudável, não pode desconsiderar a importância dos processos orgânicos que ocorrem no seu corpo e que estão diretamente ligados a sua existência no mundo. Assim, não se pode falar em humano somente pelo lado da racionalidade, do pensamento, ou da espiritualidade (não no sentido religioso), mas também naquilo que permite a sua permanência enquanto ser vivo. $\mathrm{O}$ funcionamento do corpo exige uma seleção necessária no processo de alimentação e consequente subsistência física, uma vez que nem tudo será assimilado pelo organismo ou será processado. Um exemplo simplório é a indigestão, que causa um mal-estar provocado por diversas fatores, desde o excesso de alimento até a ingestão de uma comida de má qualidade. Ou seja, tais alimentos, em excesso ou de qualidade duvidosa serão, na maioria dos casos, expulsos do corpo, pois representam possibilidades de perigo ao que se refere ao todo orgânico.

Da mesma forma age uma má lembrança sobre a psique do indivíduo. É preciso expeli-la, sob pena de, ao não fazê-lo, acarretar problemas para tal sujeito. Portanto, não se está aqui falando apenas de bem-estar ou não, mas de possibilidades de constituição de um homem saudável não apenas no sentido físico, mas também intelectual, posto que, como foi visto, muitas dessas más lembranças ou sensações são frutos, de fato, de ideologias que pregam que tal atitude, sensação ou sentimento, é errado. Tem-se, na impossibilidade de esquecimento/expurgo das lembranças/alimentos corrompidos, um homem enfermiço, incapaz de uma postura mais vigorosa e sem possibilidades de abertura para o novo, para o inédito, uma vez que não há espaço para as novas sensações e emoções, ocupadas por velhos ou enfermos sentimentos, lembranças.

Fechar temporariamente as portas e janelas da consciência permanecer imperturbado pelo barulho e a luta do nosso submundo de órgãos serviçais a cooperar e divergir; um pouco de sossego, um pouco de tabula rasa da consciência, para que novamente haja lugar para o novo (...) Eis a utilidade do esquecimento, ativo, como disse, espécie de guardião da porta, de zelador da ordem psíquica, da paz, da etiqueta (NIETZSCHE, 1998, §1, p.47).

O que o homem assimila do chamado mundo exterior passa, necessariamente, por uma seleção. É retido somente aquilo que se mostra significativo para a vida. Será, portanto, a assimilação psíquica das 
vivências a responsável pela distinção entre aquilo que irá penetrar a consciência ou o que será descartado, uma vez que se mostra impossível ao ser humano reter tudo aquilo que vive, sente, presencia.

O corpóreo, mundo particular que se agrega ao mundo externo e é por este condicionado, não está recoberto pela consciência. Ou seja, ele é, em certo sentido, autônomo: dentro de cada ser humano estão ocorrendo conflitos, reações, que estão para além da vontade humana. Mas a realidade, influencia esse corpo, bem como o contrário: sem o corpo, não há uma realidade a ser apreendida, sentida, pensada. $\mathrm{O}$ corpo projeta-se no mundo, bem como este atua também sobre o corpo, em um diálogo de possibilidades interpretativas que não se encerram.

O corpo, que carrega a consciência e dá a ela o que pensar, está por sua vez, bem distante de ser um fundamento originário e incondicionado. Ele mesmo, por um lado, é apenas "a melhor alegoria" para uma opaca e complexa pluralidade "daqueles mínimos seres com vida que constituem nosso corpo" (KGW VII, 37 [4]) e, por outro lado, é condicionado pelo "mundo", pela "existência" ("Dasein") (FW 374), pela "realidade" (KGW VIII, 11 [99] e entrelaçado com ela do início ao fim. Porém, na "realidade" também não reside nenhum fato último; ela, da sua parte, só pode ser apreendida através de um corpo, ou seja, de maneira perspectiva (STEGMAIER, 2013, p. 43).

A consciência é vista por Nietzsche como um elemento negativo, não pela coisa em si, mas o que foi a ela atribuída. Durante muito tempo, a consciência representou, em variados campos do conhecimento, o mais elevado grau do conhecimento humano. Era ela, segundo acreditava-se, a responsável pelo depuramento do intelecto humano, e, por isso, servia como referência para qualificar ou desqualificar um pensamento. Mas, conforme Barrenechea, a consciência para Nietzsche é vista de modo bastante diverso: "A consciência - considerada durante muito tempo a mais elevada característica humana - é desvalorizada, julgada uma doença, uma imperfeição (BARRENECHREA, 2009, p.92).

Nietzsche reinterpreta a consciência sob um novo olhar: para o filósofo, a consciência agora representa uma atividade dependente do todo corporal. A consciência, a despeito de toda a filosofia tradicional, está atrelada de modo indissociável ao corpo, a grande razão, para Nietzsche, desfazendo-se, desse modo, a dicotomia entre alma (ou mente) e corpo, numa hierarquia ideológica na qual a alma/mente encontrava-se um uma posição privilegiada, erro este cometido não apenas no campo religioso, mas também até mesmo científico, uma vez que a razão, fruto do puro intelecto, conforme tal ideologia, fora eleita, no terreno da técnica e da ciência, como o único elemento a ser reverenciado, ignorando o corpo como fator preponderante para a efetivação de tal conhecimento, de tal racionalidade. 
A incapacidade de efetuar a "digestão", ou seja, de olvidar, tem como resultado a transformação dos afetos em ressentimento. O indivíduo ressentido é aquele, portanto, incapaz de esquecer. No campo literário, como exemplo de tal homem, temos em Notas do Subsolo, obra do escritor eslavo Fiódor Dostoiévski, um personagem, ex-funcionário, incapaz de esquecer e que por isso atormenta-se, angustiando-se com as ofensas alheias e se mostra absolutamente incapaz de superá-las. Torna-se, por isso, ressentido e amargurado, relembrando os ultrajes sofridos, percebendo-se até mesmo certo prazer em afligir a si mesmo com ninharias, futilidades, como um esbarrão sofrido na rua, que assimila como uma ofensa e desrespeito grave.

Esse ressentimento torna o homem incapaz de reagir quando a situação assim o exige. $\mathrm{O}$ homem ressentido rumina seu sofrimento sem o desejo de eliminá-lo, de superá-lo para que possa continuar sua existência em tranquilidade. $\mathrm{O}$ ressentido prefere reviver constantemente a ofensa, a perda, a derrota, do que apresentar uma postura saudável e tentar reverter a situação de tormento, ou ao menos esquecer.

Nietzsche vê a consciência como uma espécie orgânica, similar a um estômago, pois será nela que se efetuará a separação saudável do que é benéfico ou não para a vida do indivíduo. O que se quer dizer, seguindo o raciocínio do filósofo germânico, é que o homem não pode ser considerado, eminentemente, um animal racional. Em verdade, o homem é um ente multifacetado, complexo, impulsionado por uma rede inesgotável de pulsões, termo este que Nietzsche aproxima significativamente de outro, a vontade de poder, algo sobre o qual não nos debruçaremos aqui devido o objetivo da pesquisa.

$\mathrm{Na}$ domesticação do homem, processada no decorrer da história humana, ele foi induzido a acreditar que precisa fazer promessas. Mas tal necessidade imposta revela-se uma espécie de armadilha, na qual, uma vez preso, ao homem é depositada a ideologia da responsabilidade, ao comprometimento, que em outros termos significa o cerceamento do corpo, ou seja, a dominação da sua vontade.

Perdida sua vontade, autonomia perante o mundo, o homem torna-se um encarcerado no mundo, ao qual deve se submeter de modo submisso: cumprir horários, honrar promessas, professar as leis, não questionar, aceitar as regras do jogo, os bons costumes, seguir exemplos já institucionalizados como modelos inquestionáveis. Eis o que o homem se torna mediante a perda da sua vontade e a sua respectiva domesticação através do costume.

O imenso trabalho daquilo que denominei "moralidade do costume" (cf. Aurora, $\$ 9,14,16$ ) - o autêntico trabalho do homem em si próprio, durante o período mais longo da sua existência, todo esse trabalho pré-histórico encontra nisto seu sentido, sua justificação, não obstante o que nele também haja de tirania, dureza, estupidez e idiotismo: com ajuda da 
moralidade do costume e da camisa-de-força social, o homem foi realmente tornado confiável (NIETZSCHE, 2008, §2, p.4849).

Nietzsche aponta para dois aspectos interessantes no que se refere ao processo de domesticação do homem: a moral e a sociedade. Em ambos o homem é forçado a assimilar, muitas vezes, condutas para as quais não tem afinidade natural: o trabalho, por exemplo, é imposto ao homem como a conduta exigida para todo aquele que quer ser visto como produtivo, como cidadão de bem, ou requer respeito pelo simples fato de exercer uma atividade que, em muitos casos, é benéfico somente aos que detém de fato o controle de produção. Ao funcionário resta a vida cotidiana permeada de um serviço que geralmente o desagrada, exaurindo suas forças na sustentação de um modelo social feito para beneficiar poucos em detrimento da grande maioria.

Nesse processo de domesticação, o corpo é o maior alvo: a docilidade, a resignação, o não questionamento diante das desigualdades evidentes, da exploração, conduzem o homem a assimilar uma postura na qual pouco ou nada há de extraordinário. Seu corpo, dessa forma, é utilizado para que outros ganhem com o seu esforço, com o gasto da sua energia e a debilidade do seu organismo.

A moralidade, dessa forma, não tem a função apenas de estabelecer regras a serem seguidas por toda a comunidade, mas também visa tornar o homem, conforme a visão de Nietzsche, confiável, ou seja, que não se volte contra a manipulação que sofre e que é justificada por instituições, como a Igreja e o Estado, por exemplo. Mas antes destas organizações, os costumes eram estabelecidos através da violência, da imposição. Não é sem propósito que Nietzsche afirma que a história do homem foi escrita com demasiado sangue: povos escravizados durante longos períodos precisam também de extensos períodos para o desenvolvimento de autonomia, identidade etc.

Na sociedade moderna, capitalista, fazer promessas significa contrair dívidas, efetuadas para serem pagas no decorrer de um determinado tempo. O corpo, já não mais usado como forma de pagamento de dívida nos tempos atuais (em épocas passadas uma parte do corpo era retirada do devedor como forma de pagamento quando não possuía condições de soldar seu débito) foi substituído pela classificação numérica: o indivíduo agora identificado através de números que são utilizados para representá-lo legalmente. Sua existência agora está associada a uma, duas ou três numerações que servem, entre outras coisas, como mecanismo de controle: a punição moderna para a inadimplência é, agora, a "Centralização de Serviços dos Bancos", o Serasa.

Mas a moralidade dos costumes gerou outras consequências não menos importantes para a sociedade: com ela surgiu também a crueldade, a tirania. Uma regra, ao ser estabelecida, exige a participação e aceitação, voluntária ou não, dos indivíduos que constituem determinado grupo social, 
o que não implica em dizer que todos, indistintamente, seguirão tais condutas. Com o estabelecimento de regras, surgiram também, de modo quase automático, os criminosos, ou seja, aquele que de forma consciente, ou não, recusarão, cada um a seu modo, tais imposições, posto que seus interesses particulares por vezes vão de encontro ao que é estabelecido pelo corpo social.

O criminoso, portanto, apresenta-se como um teste para a moralidade dos costumes: "O criminoso encarna para Nietzsche aquele tipo no qual a 'moralidade dos costumes' de uma sociedade se coloca à prova e se revela sintomatologicamente" (NIEMAYER, 2014, p. 119). Assim posto, o indivíduo que se posiciona contrário à moralidade é de um ângulo bastante excepcional, uma vez que a imagem criada sobre tal tipo variou no decorrer do tempo: um indivíduo que rompe com a moralidade de um pequeno grupo social no qual está inserido certamente causa mais incômodo e perplexidade do que se fizesse parte de uma comunidade maior.

Nietzsche entrevê o criminoso como uma espécie de devedor, ao qual será imposto um cruel castigo, pois desse transgressor serão retirados todos os benefícios estipulados pela sociedade, situando-o, desse modo, à margem dos benefícios sociais. Perante o credor e diante dos outros membros da comunidade, aquele contraventor é visto como o "outro", em uma guerra, ou seja, como o inimigo que não tem direito à defesa, pois já não faz mais parte do corpo social. Sobre o assunto, fala-nos Nietzsche:

O criminoso é um devedor que não só não paga os proveitos e adiantamentos que lhe foram concedidos, como inclusive atenta contra seu credor: daí que ele não apenas será privado de todos esses benefícios e vantagens, como é justo - doravante lhe será lembrado o quanto valem esse benefícios. A ira do credor prejudicado, a comunidade, o devolve ao estado selvagem e fora-da-lei do qual ele foi até então protegido: afasta-o de si - toda espécie de hostilidade poderá então se abater sobre ele (NIETZSCHE, 1998, §9, p.61).

O castigo é enfático, dependendo-se da gravidade da contravenção cometida: em muitas sociedades a pena de morte, ainda nos dias atuais, é validada nos moldes jurídicos, mas isso não significa dizer que a eliminação de tal criminoso se efetuará somente por meios legais, conforme os preceitos estabelecidos pelos órgãos controladores da sociedade $\mathrm{e}$ responsáveis pela manutenção da organização e coesão de tal grupo, a própria massa também apresenta sua própria lógica diante do criminoso: não são poucos os exemplos, disseminados por vias televisivas, radiofônicas ou jornais e revistas, sobre casos de linchamento de determinado transgressor, violador ou facínora.

A eliminação do corpo, ainda hoje, é considerada uma das principais formas de castigo para com aquele que transgride as leis de forma extrema. O corpo representa o invólucro da força vital do homem e será neste ponto 
que a cobrança da dívida será efetivada: o criminoso, extinto, paga o seu débito para com aquela sociedade que havia burlado ao transgredir o costume moral local.

Eliminar o criminoso, entretanto, não tem o único objetivo de saciar o desejo de um determinado grupo social ultrajado; também tem, entre outras funções, a de demonstrar o poder dessa mesma comunidade, uma vez que a eliminação física do indivíduo delituoso representa uma forma de aviso para os demais criminosos em potencial.

Por causa do rompimento fundamental do criminoso com o todo social, a comunidade responde como se tivesse encontrado uma ameaça "selvagem". Punições cruéis são ao mesmo tempo uma defesa e uma "celebração" do valor e do poder da comunidade. Por isso, diz Nietzsche, o criminoso "não apenas tem confiscados todos os direitos e salvaguardas, mas toda piedade também" (HATAB, 2010, p. 106).

Ao romper com a identidade moral de uma determinada sociedade, o criminoso é exposto a uma postura que, em alguns casos, se mostra mais cruel do que o próprio meliante. Em uma sociedade, como a moderna, baseada no capitalismo voraz, que prega de modo intenso e incansável o consumismo desenfreado, cria-se a ideologia do consumismo como uma representação de uma necessidade imperiosa do homem em adquirir bens duráveis ou não. O tipo criminoso, destituído de possibilidades concretas de se inserir em tal lógica de consumo, busca outros meios para tentar suprir um desejo que, inicialmente, não é seu, mas que mediante as propagandas e outras formas de convencimento e manipulação em massa, acaba se tornando imperiosas enquanto estilo de vida, de se vestir, de se alimentar, que poucos conseguem sustentar. Nesse ponto, retoma-se diretamente a questão do corpo, pois é através deste e da sua forma de exposição que, no mundo contemporâneo, julga-se o homem: a roupa que o representa deve trazer a marca da modernidade e do bom gosto, a comida, sofisticada, é feita para um paladar requintado e exigente, as residências não podem apenas abrigar das intempéries naturais, é preciso expressar magnitude e poder, principalmente econômico.

A intenção aqui não é a de se aprofundar em tais questões, mas mostrar como o corpo encontra-se indissoluvelmente interligado com questões em que antes não era mencionado sequer superficialmente. Desde ideologias dominantes até atos de crueldade, legais ou não, o corpo se faz presente, não de modo acabado, definível instantaneamente através de conceitos ou concepções que tentam situar o corpo em limites claros e rígidos. "Alma", "matéria", "tecido", "órgão" etc., tentar dar conta da complexidade desse todo que não pode ser fixado tal como se procede com uma máquina: 
O que quer que se provenha do estômago, dos intestinos, da batida do coração, dos nervos, da bílis, do sêmen - todas as indisposições, fraquezas, irritações, todos os acasos de uma máquina que conhecemos tão pouco! - tudo isso um cristão como Pascal tem de considerar um fenômeno moral e religioso, perguntando se ali se acha Deus ou o Diabo, o bem ou o mal, a salvação ou a danação. Oh, intérprete infeliz! Como precisa revirar e torturar seu sistema! Como ele próprio necessita revirar-se e torturar-se para ter razão (NIETZSCHE, 2004, §86, p.66).

O homem, através da sua corporificação, está livre: liberto das dicotomias, do materialismo redutor e simplificador, que tende a definir isto ou aquilo como bom ou ruim, certo ou errado. O corpo representa, para Nietzsche, possibilidade, perspectiva infinita de se posicionar em um mundo que também se encontra em constante e inesgotável mudança. A tentativa de reclusão do homem gerou doença, impotência diante daquilo que se pode fazer, mas que leis, regras, valores morais o impedem de realizar. Refreiamse os impulsos e temos a consciência tornada enferma. Retenham-se os ditames impostos na memória e temos um homem incapaz de lançar-se ao mundo como perspectiva. A liberdade não se apresenta através do flagelamento físico para o gozo divino, tortura que não eleva espiritualmente e nem posiciona o homem em um patamar mais próximo do sagrado, ao contrário, torna-o refém de ideias que há muito se desviaram da busca do homem pela sacralidade, não representada através de uma divindade onipresente, mas sim na experiência catártica do homem em relação à sua existência, no seu contato consigo e com a alteridade.

O mundo é vida, vontade de potência: "Ficamos livres da materialidade!" O mundo é vida, vontade de potência; esse mundo está aberto às infinitas possibilidades, à contínua mudança de forças. Nada se estabiliza, nada se fixa: tudo está em movimento, conforme a dinâmica da vontade de potência. E o homem? Como fica ele nesse turbilhão, nesse incessante dinamismo? Ao afirmar o caráter corporal do homem, estamos longe de assinalar que ele é natureza material: ele deixa de ser um "ente ideal", como sustentava o idealismo, mas tampouco pode ser considerado como um "ente material". Ao proclamarse a corporeidade do homem, em vez de assinalar a sua materialidade, resgata-se a sua multiplicidade, sua incessante diversidade, seu polipsiquismo. Daí que Nietzsche celebre isso como uma libertação (BARRENECHEA, 2009, p.135).

\section{Referências bibliográficas}

BARRENECHEA, M. A. Nietzsche: a memória, o esquecimento e a alegria da superficialidade In: MARTINS, A. M. S. [et al.] Nietzsche e o gregos: arte, memória e educação, assim falou Nietzsche V. Rio de Janeiro: DP\&A: Faperj: Unirio: Brasília, DF: Capes, 2006. 
. Nietzsche e o corpo. Rio de Janeiro: 7 Letras, 2009.

COURTINE, J. J. Decifrar o corpo: pensar com Foucault. Tradução de Francisco Morás. Petrópolis, RJ: Vozes, 2013.

GIACÓIA JUNIOR, O. Nietzsche: o humano como memória e como promessa. Petrópolis, RJ: Vozes, 2013.

HATAB, L. J. Genealogia da Moral de Nietzsche: uma introdução. Tradução Nancy Juozapavicius. São Paulo: Madras, 2010.

NIEMEYER, C. (Org.) Léxico de Nietzsche. São Paulo: Edições Loyola, 2014.

NIETZSCHE, F. Genealogia da Moral: uma polêmica. Tradução, notas e posfácio Paulo César de

Souza. São Paulo: Companhia das Letras, 1998.

STEGMAIER, W. As Linhas Fundamentais do Pensamento de Nietzsche: coletânea de artigos 1985-2009. Organização de Jorge Luiz Viesenteiner e André Luis Muniz Garcia. Petrópolis, RJ: Vozes, 2013. 